\title{
Research on Regional Economic Vitality and Its Influencing Factors
}

\author{
Yuyu Wu \\ Anhui University of Finance and Economics, Bengbu, China \\ Email: wyy20000126@126.com
}

How to cite this paper: $\mathrm{Wu}$, Y.Y. (2020) Research on Regional Economic Vitality and Its Influencing Factors. Open Journal of Social Sciences, 8, 217-233.

https://doi.org/10.4236/jss.2020.81015

Received: December 30, 2019

Accepted: January 11, 2020

Published: January 14, 2020

Copyright $\odot 2020$ by author(s) and Scientific Research Publishing Inc. This work is licensed under the Creative Commons Attribution International License (CC BY 4.0).

http://creativecommons.org/licenses/by/4.0/

\begin{abstract}
To study the evaluation and influencing factors of regional economic vitality, this paper uses factor analysis method to grasp the key factors affecting economic vitality, and then establishes a multiple regression model. We comprehensively use SPSS, Eviews, Excel and other software programmings, figuring out the effects of population, enterprise vitality, and policy transformation on economic vitality. At last, we put forward some reasonable suggestions to promote the sustainable development of economy.
\end{abstract}

\section{Keywords}

Regional Economic Vitality, Factor Analysis, Multiple Regression Model, SPSS, Eviews

\section{Introduction}

\subsection{Background}

China's economic development has stepped into a new normal, which is in the "three stages superposition" stage of growth shift, economic adjustment pain and early stimulus policy digestion. The downward pressure of macro-economy has increased [1]. Local governments have successively issued many preferential policies to improve regional economic vitality, but the similarities and differences of regional resource endowments make some policies ineffective. How to grasp and influence economic activities? The key factor of strength is to study how to improve the vitality of regional economy.

\subsection{Problem Statement and Analysis}

\subsubsection{Problem Statement}

Problem one requires us to select appropriate indicators, establish a measure- 
ment system of economic vitality, analyze its influencing factors, and formulate feasible plans to promote regional economic vitality. At the same time, taking a specific region as an example, this paper analyzes the impact of population and enterprise vitality on the change of regional economic vitality. Referring to the previous literature, this paper will select indicators from nine aspects: economic benefits, human resources, government regulation, enterprise vitality (measured by enterprise survival rate and enterprise profit), industrial structure upgrading, opening up, quality of life of residents, scientific and technological innovation and environment, use factor analysis method to grasp the key factors to establish a measurement model, and finally give the line to enhance regional economic vitality Action plan. On this basis, the population and enterprise vitality as explanatory variables for multiple regression can be used to quantitatively analyze the role of these two factors.

The second problem requires us to establish a mathematical model between local economic policies and economic vitality to study the short-term and long-term impact of the transformation of local economic policies on regional economic vitality. This paper focuses on the effect of government fiscal policy. On the basis of question one, the lagging term of fiscal policy is introduced into the model as an explanatory variable, and finally the short-term and long-term effects of government fiscal policy on regional economic vitality are obtained.

The third problem requires us to first select the appropriate indicators, establish a mathematical model to measure the regional economic vitality, and then rank the economic vitality of 19 cities. Based on the research results of question 1 , the paper uses three key factors of social production, consumption and industrial structure to measure the economic vitality of 19 cities, calculate the comprehensive score and give the final ranking.

\subsubsection{Overall Analysis}

- Establish a suitable index system to measure the regional economic vitality, and take a region as an example, analyze the impact of population and enterprise vitality, and formulate action plans to improve the regional economic vitality;

- Taking a specific region as the research object, this paper establishes a mathematical model of policy variables on regional economic vitality, and analyzes the short-term and long-term impact of economic policy transformation;

- Select the appropriate index system and establish a mathematical model to rank the economic vitality of 19 cities;

- According to the above research results, this paper puts forward some targeted suggestions to the cities in question 2 , in order to promote the sustainable development of regional economy and improve regional competitiveness.

Figure 1 is the overall flow chart of problem solving ideas. 


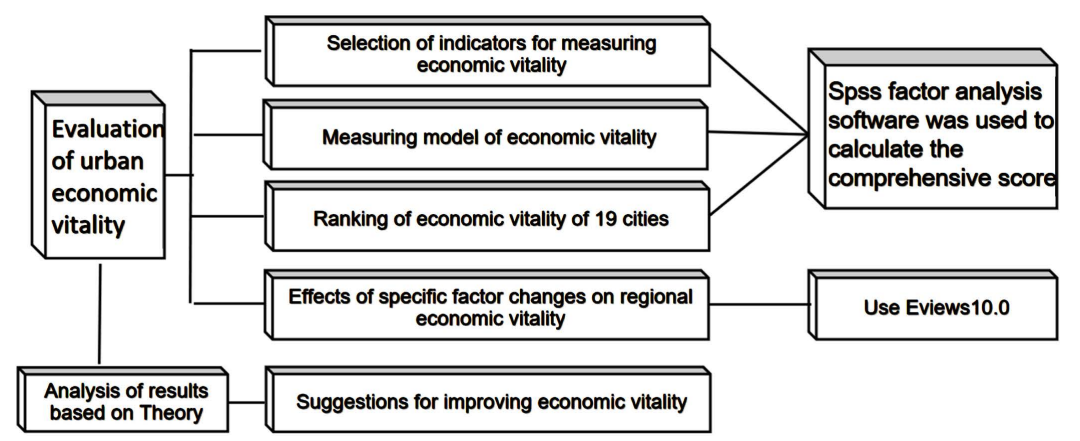

Figure 1. Overall solution flow chart.

\section{Model Preparation}

\subsection{Basic Assumptions}

- Economic vitality is an elastic variable, that is, when the economic environment of a region changes, the economic vitality of the region will change immediately [2];

- Human resources in a region can be measured by the number of permanent residents;

- The government only stimulates the economy through fiscal policy, not considering the influence of other government regulation tools such as monetary policy [3].

\subsection{Symbols}

Variable symbols and descriptions are shown in Table 1.

\section{Model Establishment \& Solvation}

\subsection{Task 1 Define Economic Vitality}

\subsubsection{Indicators Selection}

In biology, vitality refers to the vitality of a system. It is generally believed that the more frequent the energy input, conversion and output, the higher the vitality of a system. Comparing the concept of vitality to the field of economics, it can be considered that the economic development of a region is sustainable and stable development, and it has strong economic vitality [4]. According to this, this paper defines the regional economic vitality as the index to measure the regional development ability. Based on the principles of data availability, representativeness and comprehensiveness, this paper discusses the economic benefits, human resources, government regulation, enterprise vitality (measured by enterprise survival rate and enterprise profit), industrial structure upgrading, opening up, quality of life of residents, science and technology Innovation and environment are 9 aspects to select indicators and build the following description system [5] (see Figure 2).

\subsubsection{Model Establishing and Solving}

Based on the annual data of 19 different cities, this paper uses 13 selected 


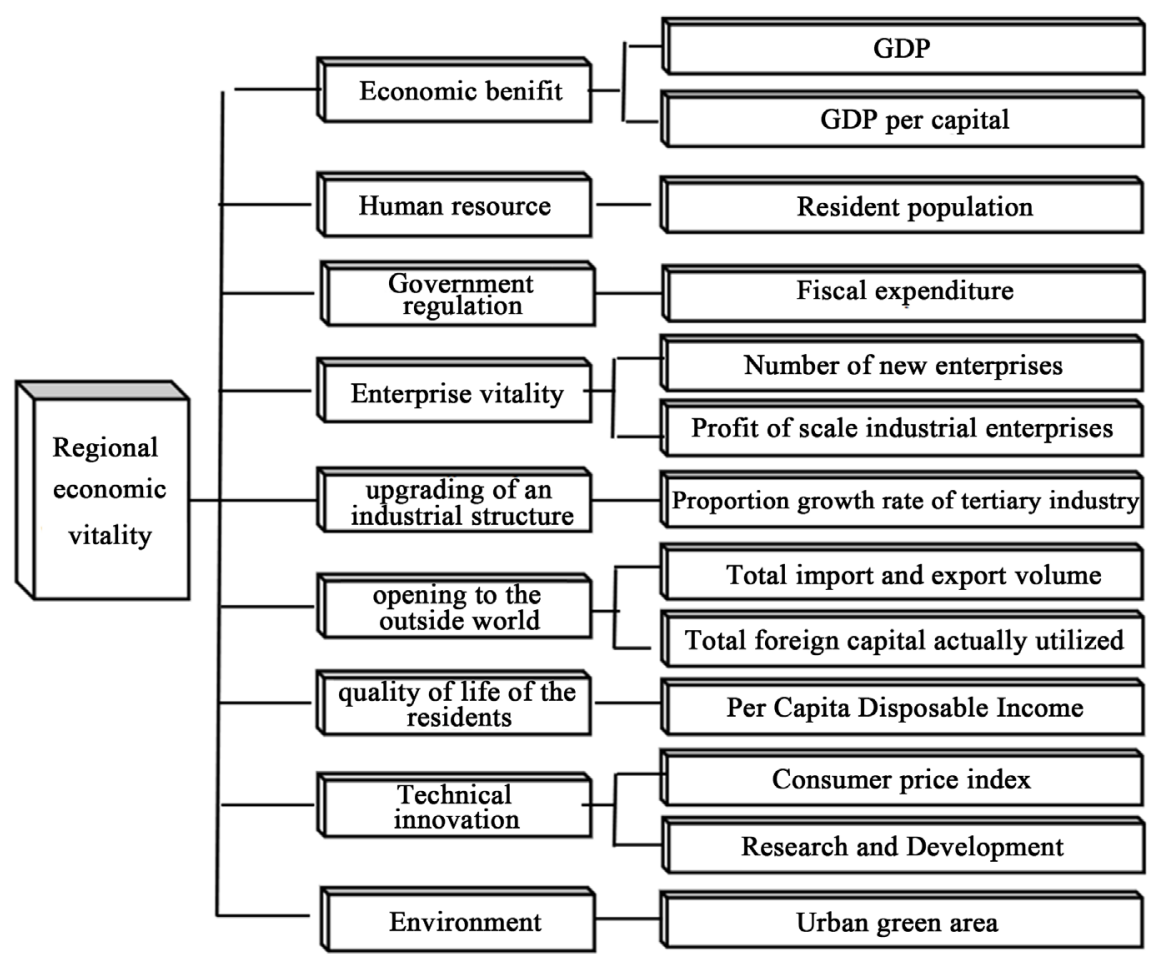

Figure 2. Indicators for measuring regional economic vitality.

Table 1. Variables and their meanings.

\begin{tabular}{ccc}
\hline Number & Symbols & Symbol description \\
\hline 1 & eco & Economic vitality \\
2 & gdp & Gross domestic product \\
3 & pgdp & Per capital gross domestic product \\
4 & rp & Resident population \\
5 & be & Budgetary expenditure \\
6 & eir & Enterprise survival rate \\
7 & pro & Profit \\
8 & dts & Ratio of tertiary industry to GDP increasement \\
9 & tme & Total imports and exports \\
10 & fc & Foreign capital used \\
11 & pdi & Per capita disposable income \\
12 & cpi & Consumer price index \\
13 & rd & ugs \\
14 & & Research and experimental development fund
\end{tabular}

indicators to calculate the comprehensive indicators of regional economic vitality. In order to avoid the lower kmo value caused by the low correlation of some indicators, $\mathrm{KMO}$ and Bartlett tests are carried out for the data in advance, and the test results are shown in Table 2. 
Table 2. KMO and Bartlett's test.

\begin{tabular}{lcc}
\hline \multicolumn{2}{c}{ Kaiser-Meyer-Olkin Measure of Sampling Adequacy. } & 0.525 \\
\hline & Approx. Chi-Square & 204.204 \\
Bartlett's Test of Sphericity & df & 78 \\
& Sig. & 0.000 \\
\hline
\end{tabular}

It can be seen that the kmo statistic value is relatively small, which does not reach the pass threshold value of kmo, and some variable data with low correlation need to be eliminated. It is considered that kmo and Bartlett tests will be carried out again after the research of consumer price index and common factor with low correlation with GDP is removed from the experimental development funds and urban green area. The results are shown in Table 3. It can be found that kmo value is increased to 0.714 , greater than 0.7 , and SIG is 0.000 , that is to say, under the significance level of $1 \%$, the original spherical hypothesis can be rejected. Therefore, the remaining 10 indicators are not independent. It is basically appropriate to use adjusted data for factor analysis.

The larger the variance of extracting common factors among variables, the stronger the ability of common factor interpretation. Observe Table 4, it can be seen that the common factors extracted from all variables can explain most of the explanatory variables more than $70 \%$, so it is considered that the loss of the original data is low and the effect of common factor extraction is good. Continue to use SPSS software to analyze the factor whose characteristic root is greater than 1 , and finally get three factors. The cumulative variance contribution rate of the three factors in Table 5 is $80.67 \%$, indicating that the three factors contain $80.67 \%$ of all index information. In addition, observing the scree plot (see Figure 3 ), it is found that the broken line corresponding to the information contributed by the three factors is relatively steep, while the broken line after is relatively gentle, which can show that the extraction of the three factors is reasonable and effective.

By observing Table 6, it can be found that factor 1 is mainly composed of the total regional economic output value, local government financial expenditure, enterprise profit and the amount of foreign capital actually utilized. The total regional economic output value and enterprise profit reflect the social production status, while the local financial expenditure and the amount of foreign capital actually utilized reflect the funds that can be used for social production, so factor 1 is named as social production factor; factor 2 is mainly composed of per capita disposable income and enterprise survival rate. Disposable income determines the upper limit of residents' consumption ability, while enterprise survival rate will affect residents' expectation of future income through employment, thus affecting the current consumption level, so factor 2 is named as consumption factor; factor 3 is mainly the added value of the ratio of tertiary industry to GDP So factor 3 is called industrial structure factor.

From Table 7, the expression of the factor is as follows: 


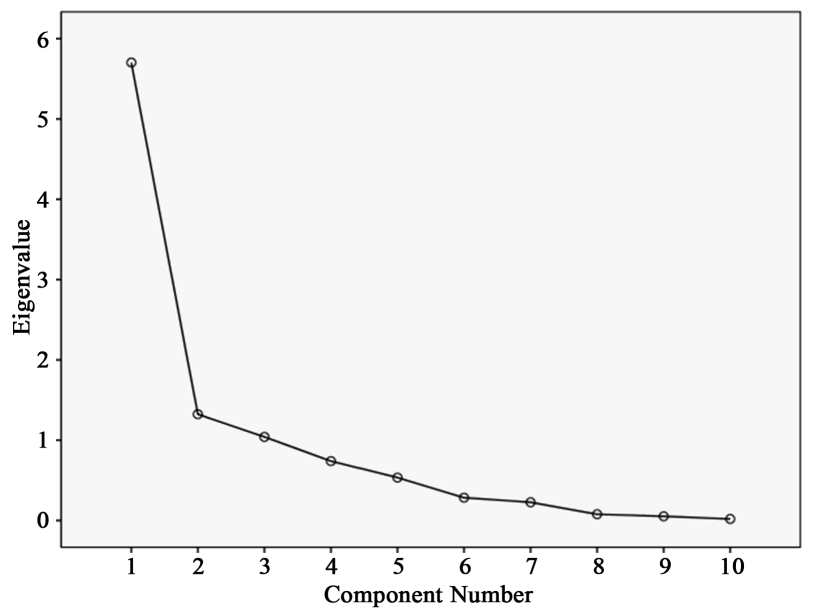

Figure 3. Scree plot.

Table 3. KMO and Bartlett's test.

\begin{tabular}{lcc}
\hline \multicolumn{2}{c}{ Kaiser-Meyer-Olkin Measure of Sampling Adequacy. } & 0.714 \\
\hline & Approx. Chi-Square & 153.463 \\
Bartlett's Test of Sphericity & $\mathrm{df}$ & 45 \\
& Sig. & 0.000 \\
\hline
\end{tabular}

Table 4. Communalities.

\begin{tabular}{ccc}
\hline & Initial & Extraction \\
\hline gdp & 1.000 & 0.915 \\
pgdp & 1.000 & 0.814 \\
rp & 1.000 & 0.619 \\
be & 1.000 & 0.970 \\
eir & 1.000 & 0.575 \\
pro & 1.000 & 0.881 \\
dts & 1.000 & 0.953 \\
tme & 1.000 & 0.818 \\
fc & 1.000 & 0.729 \\
pdi & 1.000 & 0.793 \\
\hline
\end{tabular}

Table 5. Total variance explained.

\begin{tabular}{|c|c|c|c|c|c|c|c|c|c|}
\hline \multirow{2}{*}{ Component } & \multicolumn{3}{|c|}{ Initial Eigenvalues } & \multicolumn{3}{|c|}{ Extraction Sums of Squared Loadings } & \multicolumn{3}{|c|}{ Rotation Sums of Squared Loadings } \\
\hline & Total & $\%$ of Variance & Cumulative \% & Total & $\%$ of Variance & Cumulative \% & Total & $\%$ of Variance & Cumulative $\%$ \\
\hline 1 & 5.703 & 57.029 & 57.029 & 5.703 & 57.029 & 57.029 & 4.557 & 45.565 & 45.565 \\
\hline 2 & 1.323 & 13.233 & 70.262 & 1.323 & 13.233 & 70.262 & 2.372 & 23.719 & 69.285 \\
\hline 3 & 1.041 & 10.410 & 80.672 & 1.041 & 10.410 & 80.672 & 1.139 & 11.387 & 80.672 \\
\hline 4 & 0.739 & 7.394 & 88.065 & & & & & & \\
\hline 5 & 0.534 & 5.338 & 93.404 & & & & & & \\
\hline 6 & 0.284 & 2.838 & 96.241 & & & & & & \\
\hline 7 & 0.227 & 2.271 & 98.512 & & & & & & \\
\hline 8 & 0.078 & 0.777 & 99.289 & & & & & & \\
\hline 9 & 0.052 & 0.524 & 99.813 & & & & & & \\
\hline 10 & 0.019 & 0.187 & 100.000 & & & & & & \\
\hline
\end{tabular}


Table 6. Rotated component matrix.

\begin{tabular}{cccc}
\hline & \multicolumn{3}{c}{ Component } \\
\cline { 2 - 4 } gdp & 1 & 2 & 3 \\
\hline pgdp & 0.887 & 0.328 & -0.142 \\
rp & 0.209 & 0.876 & -0.052 \\
be & 0.782 & 0.088 & -0.008 \\
eir & 0.978 & 0.087 & -0.071 \\
pro & 0.101 & 0.740 & 0.133 \\
dts & 0.839 & 0.402 & -0.124 \\
tme & -0.065 & -0.009 & 0.974 \\
fc & 0.756 & 0.447 & -0.215 \\
pdi & 0.829 & 0.184 & 0.088 \\
\hline
\end{tabular}

Table 7. Component score coefficient matrix.

\begin{tabular}{cccc}
\hline & \multicolumn{3}{c}{ Component } \\
\cline { 2 - 4 } gdp & 1 & 2 & 3 \\
\hline pgdp & 0.199 & -0.021 & -0.031 \\
rp & -0.148 & 0.488 & 0.025 \\
be & 0.235 & -0.135 & 0.071 \\
eir & 0.294 & -0.188 & 0.030 \\
pro & -0.134 & 0.442 & 0.181 \\
dts & 0.167 & 0.037 & -0.014 \\
tme & 0.072 & 0.072 & 0.913 \\
fc & 0.121 & 0.080 & -0.104 \\
pdi & 0.236 & -0.081 & 0.171 \\
\hline
\end{tabular}

$$
\begin{gathered}
F_{1}=0.199 g d p+\cdots-0.064 p d i \\
F_{2}=-0.021 g d p+\cdots+0.034 p d i \\
F_{3}=-0.031 g d p+\cdots-0.172 p d i
\end{gathered}
$$

Taking the variance contribution rate of each factor as the weight, we finally get the measurement model of regional economic vitality:

$$
E C O=0.707 * F_{1}+0.164 * F_{2}+0.129 * F_{3}
$$

\subsubsection{Three Key Factors to Measure Economic Vitality}

Based on the above research results and three key factors extracted, this paper makes the following action plan to improve the vitality of regional economy and promote the sustainable and healthy development of local economy: 1) local 
finance serves the development of real economy. The real economy is the lifeblood of the national economy, and the development of Finance and real economy complement each other. At present, there are still constraints in Shanghai's financial service real economy. According to these constraints, it is proposed to improve the system construction of financial service real economy, improve the efficiency of financial service real economy, increase the incentives of financial service real economy, guard against the risks of local financial service real economy, and promote local financial coordination with industrial policies to serve the real economy. Second, improve the social security system, so that residents dare to consume; 2) optimize the industrial structure. Shanghai municipal government develops new service industries and new formats with high income demand elasticity, and promotes the upgrading of the tertiary industry structure. Service industry is the basic tertiary industry in the national economic system. With the increase of national income, people's consumption is constantly upgrading. In the future, the demand for production and life will develop in the direction of differentiation, diversification and advancement, and the service industry will also take the road of specialization, personalization and high-end development. As a pillar industry in the future, the tertiary industry should focus on developing service industry and enjoying service industry with large income demand elasticity, encourage people to find new service direction and service demand in the new situation of economic transformation, build a new economic growth point of the tertiary industry in the future and promote the optimization and upgrading of the tertiary industry structure by opening up new service industry and new formats [6].

\subsection{Task 2 Impact of Population and Enterprise Vitality}

\subsubsection{Model Establishing and Solving}

Specifically analyze the impact of population and enterprise vitality on regional economic vitality. This paper selects Shanghai as the research object, takes eco as the explanatory variable, GDP, RP, eir and Pro as explanatory variables, and constructs the following multiple regression model:

$$
\text { eco }=\alpha+\beta_{i} X_{i}+\varepsilon
$$

where " $\alpha$ " is a constant term, $i=1,2,3,4$, " $X_{i}^{\prime \prime}$ refers to the factor vector listed above to describe the regional economic vitality, " $\beta_{i}$ " refers to the coefficient vector of " $X_{i}^{\prime}$ " and " $\varepsilon$ " refers to the random error term.

1) Description line statistics

First of all, in order to understand the distribution characteristics of variable data, descriptive statistical analysis was carried out on the data, and the results are shown in Table 8.

2) Correlation analysis

After descriptive statistics of the samples, correlation analysis of the data (see Table 9). Because the data in this paper are all numerical data, Pearson correlation coefficient can be used to measure the correlation between variables. If the 
Table 8. Descriptive statistics.

\begin{tabular}{ccccc}
\hline & Minimum & Maximum & Mean & Std. Deviation \\
\hline gdp & $14,069.87$ & $32,679.87$ & $22,362.48$ & 6050.74 \\
rp & 1391.04 & 1462.38 & 1430.16 & 22.67 \\
eir & $72.86 \%$ & $77.43 \%$ & $75.8691 \%$ & $1.65259 \%$ \\
pro & 977.57 & 3350.44 & 2371.20 & 712.88 \\
\hline
\end{tabular}

Table 9. Correlation.

\begin{tabular}{cccccc}
\hline & ECO & GDP & RP & EIR & PRO \\
\hline ECO & 1 & & & & \\
GDP & 0.783 & & & & \\
RP & 0.840 & 0.439 & 1 & & \\
EIR & 0.920 & 0.236 & 0.140 & 1 & 1 \\
PRO & 0.842 & 0.147 & 0.074 & 0.213 & \\
\hline
\end{tabular}

Attention: the correlation coefficient corresponding to strong correlation is greater than 0.8 .

correlation between the explanatory variable and the interpreted variable is high, it indicates that the research model is appropriate, and if the correlation between the explanatory variables is too high, it may cause serious multicollinearity between variables and affect the effectiveness of the model. From the results of correlation analysis, all the explanatory variables selected by the model have strong correlation with the explanatory variables, and there is no strong correlation between the explanatory variables.

3) Regression analysis of the model

The multiple decision coefficient " $R$ " $=0.542$, the modified decision coefficient " $\mathrm{R}^{2 "}=0.9203$, the F statistic is 121.3072 (see Table 10), and the residual analysis diagram (see Figure 4) of the model shows that the overall fitting degree of the model is good, and the joint influence of the explanatory variables on the explanatory variables is significant. Given the level of significance " $\alpha=0.05$ ”, looking up the " $\mathrm{t}$ " distribution table with 14 degrees of freedom, the critical value of t-statistics " 4.6041 " is obtained. The $t$-values of the explanatory variables selected in the model are all greater than the critical value. Therefore, it is considered that the influence of single explanatory variable on the explanatory variable is also significant.

\subsubsection{Summary}

From the perspective of regional resident population, the estimated parameters are significantly positive, which shows that under other constant conditions, the more population a city has, the stronger the economic vitality of the region. This is consistent with the actual situation. Generally, the more the population is, the more the consumption expenditure will be. As one of the three carriages to promote economic growth, consumption obviously plays a role in promoting regional economic vitality. 


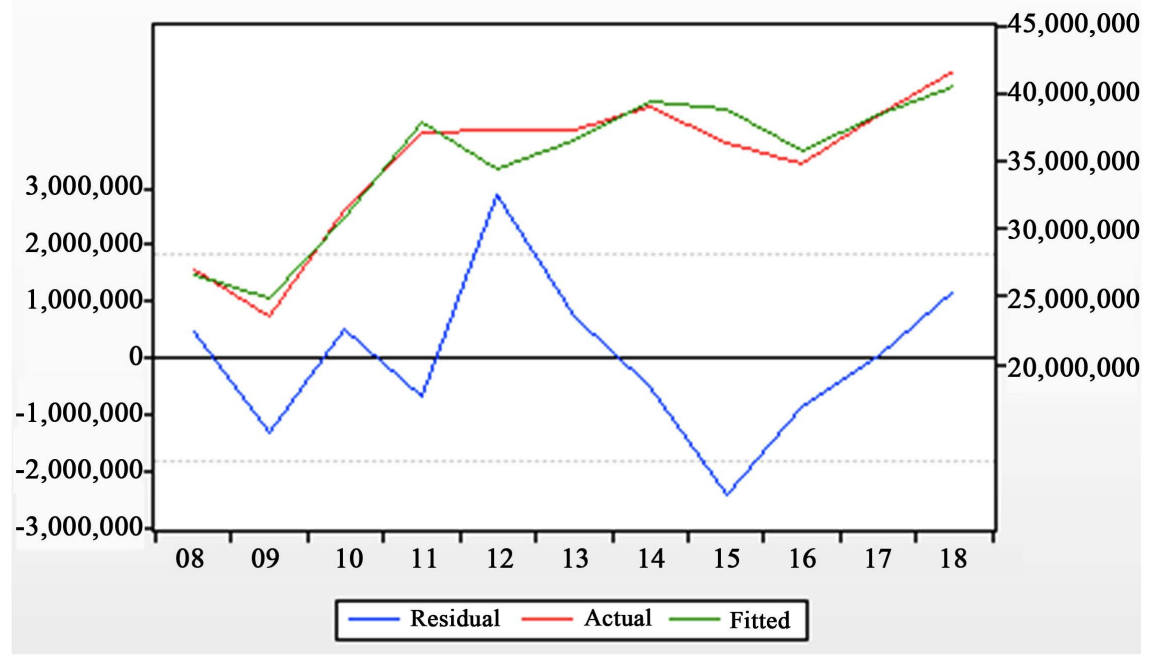

Figure 4. Residual analysis chart.

Table 10. Model regression results.

\begin{tabular}{ccccc}
\hline Variable & Coefficient & Std. Error & t-Statistic & Prob. \\
\hline C & $7.26 \mathrm{E}+08$ & $3.76 \mathrm{E}+08$ & 1.929761 & 0.0019 \\
GDP & 1855.823 & 813.9979 & 4.279887 & 0.0478 \\
RP & $759,651.4$ & $324,943.6$ & -5.337795 & 0.0280 \\
EIR & $4.46 \mathrm{E}+08$ & $1.09 \mathrm{E}+08$ & 6.078675 & 0.0065 \\
PRO & 6677.099 & 3744.899 & 4.782985 & 0.0449 \\
R-squared & 0.954231 & Mean dependent var & $34,888,955$ \\
Adjusted R-squared & 0.920385 & S.D. dependent var & $5,477,611$ \\
S.E. of regression & 1813535. & Akaike info criterion & 31.96241 \\
Sum squared resid & $1.97 \mathrm{E}+13$ & Schwarz criterion & 32.14327 \\
Log likelihood & -170.7933 & Hannan-Quinn criter & 31.84840 \\
F-statistic & 121.30712 & Durbin-Watson stat & 1.759879 \\
Prob (F-statistic) & 0.001082 & &
\end{tabular}

From the perspective of enterprise vitality, this paper uses two indicators of enterprise survival rate and enterprise profit to measure enterprise vitality, and the relevant estimation parameters are all positive, and significant at the significance level of $5 \%$, indicating that the economic vitality of a region is closely related to the enterprise vitality, and the regions with good business conditions and strong profitability have stronger economic vitality.

\subsection{Task 3 Impact of Policy Transformation}

\subsubsection{Analysis}

This problem requires us to establish a mathematical model between local economic policies and economic vitality to study the short-term and long-term impact of the transformation of local economic policies on regional economic vi- 
tality. This paper focuses on the effect of government fiscal policy. On the basis of question one, the lagging term of fiscal policy is introduced into the model as an explanatory variable, and finally the short-term and long-term effects of government fiscal policy on regional economic vitality are obtained.

\subsubsection{Preparation}

First, cross is used, as shown in Figure 5. It can be preliminarily judged that the lag period length of fiscal policy is 1 .

\subsubsection{Model Establishing and Solving}

Use eviews 10.0 software to regress the relevant data, and the results are shown in Table 11. From it, we can see that the multiple determinable coefficient " $R$ " = 0.9627 , the modified determinable coefficient " $R$ " $=0.9381$, and the F statistic is 131.3072, which indicates that the overall fitting degree of the model is good, the common influence of the explanatory variables on the explanatory variables is significant, and the p-value of the $t$ statistic of each explanatory variable is less than 0.05 , that is to say, at the level of $5 \%$ significant thinking, all the explanatory variables can be explained The independent influence of variables on regional economic vitality is also significant.

\begin{tabular}{|c|c|c|c|c|c|c|c|c|}
\hline \multicolumn{3}{|c|}{$\mathrm{ECO}, \mathrm{BE}(-\mathrm{i})$} & \multicolumn{3}{|c|}{$\mathrm{ECO}, \mathrm{BE}(+\mathrm{i})$} & i & lag & lead \\
\hline I & & & 1 & & & 0 & 0.9205 & 0.9205 \\
\hline I & & $\square$ & I & & $\square$ & & 0.6141 & 0.6254 \\
\hline $\mathrm{I}$ & & 口 & 1 & & $\square$ & & 0.1724 & 0.2022 \\
\hline $\mathrm{I}$ & & 1 & 1 & & 1 & 3 & 0.0166 & -0.0192 \\
\hline $\mathrm{I}$ & c & 1 & 1 & ㄷ & 1 & & -0.0618 & -0.1276 \\
\hline $\mathrm{I}$ & 므 & 1 & 1 & $\square$ & 1 & & -0.1298 & -0.2845 \\
\hline I & 드 & 1 & I & $\square$ & 1 & & -0.1138 & -0.3161 \\
\hline I & C & 1 & 1 & $\square$ & 1 & & -0.0768 & -0.2152 \\
\hline I & $\square$ & 1 & 1 & ㄷ & 1 & & -0.2241 & -0.1657 \\
\hline $\mathrm{I}$ & $\square$ & 1 & 1 & $\square$ & 1 & s & -0.3283 & -0.1741 \\
\hline
\end{tabular}

Figure 5. Cross-correlation.

Table 11. Dynamic model regression results.

\begin{tabular}{ccccc}
\hline Variable & Coefficient & Std. Error & t-Statistic & Prob. \\
\hline C & $3.26 \mathrm{E}+08$ & $4.95 \mathrm{E}+08$ & 3.657853 & 0.0576 \\
GDP & 1564.327 & 1065.777 & 4.467781 & 0.0385 \\
RP & -419822.5 & $441,037.9$ & -3.951897 & 0.0114 \\
EIR & $3.56 \mathrm{E}+08$ & $1.68 \mathrm{E}+08$ & 5.116857 & 0.0246 \\
PRO & 4990.475 & 4234.036 & 4.178657 & 0.0235 \\
BE & -1653.215 & 877.5094 & -4.883985 & 0.0561 \\
BE(-1) & 371.7266 & 1410.912 & 3.263465 & 0.0093 \\
R-squared & 0.962703 & Mean dependent var & $35,684,211$ \\
Adjusted R-squared & 0.938110 & S. D. dependent var & $5,060,465$ \\
S.E. of regression & 1692723 & Akaike info criterion & 31.71760 \\
Sum squared resid & $8.60 \mathrm{E}+12$ & Schwarz criterion & 31.92941 \\
Log likelihood & -151.5880 & Hannan-Quinn criter. & 31.48525 \\
F-statistic & 131.90603 & Durbin-Watson stat & 1.851768 \\
Prob (F-statistic) & 0.030121 & & \\
\hline
\end{tabular}




\subsubsection{Policy Transformation Promotes Economic Vitality in the Long Run [7]}

First of all, the estimation parameters of fiscal expenditure and its lagged items have passed the $5 \%$ significance test, which shows that both have a great impact on the regional economic vitality, that is, it is effective for the government to use fiscal policy to intervene in the economy; secondly, from the perspective of the symbols of the estimation parameters, the regression coefficient of the current value is negative, while the regression coefficient of the lagged items is positive, which is explained as follows: government financial revenue The source is tax revenue. The government adopts expansionary fiscal policy, which means to increase the burden of taxpayers, reduce the consumption of the current period, and then talk about the economic vitality of the current period. With the capital entering the production field, the expansion of production by enterprises will improve the regional economic vitality.

Based on the above analysis, this paper holds that the economic policy transformation will inhibit the economic vitality in the short term, and promote the economic vitality in the long term. Local governments should take a long-term view and formulate economic policies in line with the long-term interests of the region.

\subsection{Task 4 Rank cities}

\subsubsection{Analysis}

This problem requires us to first select the appropriate indicators, establish a mathematical model to measure the regional economic vitality, and then rank the economic vitality of 19 cities. Based on the research results of question 1, the paper uses three key factors of social production, consumption and industrial structure to measure the economic vitality of 19 cities, calculate the comprehensive score and give the final ranking.

\subsubsection{Ranking Results}

Based on the measurement model of regional economic vitality established by model I, the scores of three key factors and comprehensive factors of 19 cities are calculated by SPSS, and then the scores are sorted by rank function of Excel to get the comprehensive ranking of regional economic vitality of 19 cities as Table 12.

It can be seen from Table 12 that the top five cities in terms of social production are Suzhou, Shenzhen, Shanghai, Guangzhou and Changsha; in terms of consumption growth rate, the top five cities are Changsha, Chongqing, Guangzhou, Shanghai and Zhengzhou; in terms of competitiveness of industrial structure, the top five cities are Shanghai, Beijing, Shenzhen, Chongqing and Changsha; finally the top five cities are: Shanghai, Shenzhen, Hangzhou, Changsha and Guangzhou.

\subsection{Task 5 Advice}

\subsubsection{Analysis}

This requires us to make suggestions to the decision-makers of the cities selected 
Table 12. Rank of comprehensive scores of urban economic vitality.

\begin{tabular}{|c|c|c|c|c|c|c|c|c|c|}
\hline City & Year & $\mathrm{F} 1$ & Rank1 & F2 & Rank2 & F3 & Rank3 & $\mathrm{F}$ & Rank \\
\hline Shanghai & 2018 & 1.27397 & 3 & 0.8157 & 4 & 1.82 & 1 & 1.26925159 & 1 \\
\hline Shenzhen & 2018 & 1.5257 & 2 & 0.11009 & 9 & 1.05 & 3 & 1.23217466 & 2 \\
\hline Beijing & 2018 & 0.38257 & 7 & 0.31595 & 8 & 1.31 & 2 & 0.49128279 & 6 \\
\hline Guangzhou & 2018 & 0.97259 & 4 & 0.95555 & 3 & -0.15 & 9 & 0.82498133 & 5 \\
\hline Chongqing & 2018 & -2.21879 & 19 & 1.05763 & 2 & 0.84 & 4 & -1.2868732 & 19 \\
\hline Chengdu & 2018 & 0.20763 & 10 & -0.13554 & 12 & -0.12 & 8 & 0.10908585 & 10 \\
\hline Nanjing & 2018 & 0.24688 & 9 & 0.32671 & 7 & -0.42 & 15 & 0.1739446 & 8 \\
\hline Hangzhou & 2018 & 0.58133 & 6 & -0.4247 & 14 & -0.37 & 13 & 0.29361951 & 7 \\
\hline Suzhou & 2018 & 1.80422 & 1 & -0.65262 & 17 & -0.05 & 6 & 1.16210386 & 3 \\
\hline Tianjin & 2018 & -0.79263 & 15 & -1.11658 & 19 & -0.24 & 10 & -0.7744685 & 15 \\
\hline Qingdao & 2018 & -0.0989 & 13 & -0.04564 & 11 & -0.3 & 12 & -0.1161073 & 14 \\
\hline Dongguan & 2018 & 0.32506 & 8 & -0.23759 & 13 & -0.42 & 15 & 0.13667266 & 9 \\
\hline Zhengzhou & 2018 & -0.14404 & 14 & 0.76674 & 5 & -0.28 & 11 & -0.0122109 & 12 \\
\hline Wuhan & 2018 & -0.02655 & 12 & 0.38315 & 6 & -0.06 & 7 & 0.03632575 & 11 \\
\hline Xi'an & 2018 & -1.03589 & 16 & 0.07653 & 10 & -0.59 & 17 & -0.7959333 & 16 \\
\hline Ningbo & 2018 & 0.09359 & 11 & -0.44946 & 15 & -0.41 & 14 & -0.0604333 & 13 \\
\hline Changsha & 2018 & 0.74695 & 5 & 3.44291 & 1 & 0.18 & 5 & 1.11595089 & 4 \\
\hline Shenyang & 2018 & -1.48729 & 18 & -0.62121 & 16 & -0.79 & 18 & -1.2553025 & 18 \\
\hline Kunming & 2018 & -1.1564 & 17 & -0.76716 & 18 & -1 & 19 & -1.072389 & 17 \\
\hline
\end{tabular}

in question 2 on how to promote the sustainable development of regional economy and improve regional competitiveness. On the basis of the above research results, this paper looks up a large number of materials and gives reasonable opinions in combination with the reality of life.

\subsubsection{The Way to Improve Economic Vitality of Shanghai}

At present, China's economy is on the track of new normalization development, in the period of speed change, the period of economic adjustment pains and the period of digestion of early stimulus policies. In response to the huge downward pressure of macro-economy, local governments have issued policies to stimulate the economy, and blind expansion policies often bring high input and low efficiency growth [8]. Therefore, combined with the research results of this paper, we put forward some suggestions to the Shanghai municipal government, in order to promote the sustainable and healthy development of Shanghai's economy.

1) Adjust and optimize the industrial structure-vigorously develop the tertiary industry [9]

The third industry is an important symbol of urban economic development. Compared with the primary industry and the secondary industry, the tertiary industry has the characteristics of less investment, short cycle, quick effect and 
high wage income of the employees. The unbalanced development of the three industries in Shanghai and the active development of the third industry can not only strengthen the overall quality culture in the region, but also promote the transformation of agricultural society to industrial society and improve agricultural productivity.

2) Reasonable distribution of financial expenditure

The reasonable structure of fiscal expenditure and the coordination of distribution proportion are of great significance to regional economic development. A certain amount of fiscal revenue can promote good economic development, but if the fiscal revenue is excessive, it will have a negative impact on social economy. Therefore, the Shanghai municipal government should pay attention to the direction of fiscal expenditure on the basis of the relevant national tax system and the continuous and stable growth of local income. The government should increase its investment in public infrastructure to avoid the crowding out effect on private investment and foreign investment.

3) Increase the investment of scientific and technological funds and scientific research personnel

Increasing the investment of science and technology funds and scientific researchers is the foundation and premise of vigorously developing high-tech industry and enhancing the ability of technological innovation. Shanghai municipal government and enterprises should realize the importance of scientific research funds and scientific researchers. While increasing the investment of scientific research funds, they should also actively carry out technological innovation activities to attract high-tech talents. Thirdly, they should vigorously advocate entrepreneurship and establish their own country. At the same time, successful entrepreneurs and role models provide necessary social security for entrepreneurs and young people, including the establishment of entrepreneurship security fund, minimum living security fund, entrepreneurship guidance mechanism, etc. to let young people show their youthful vitality in innovation and entrepreneurship.

4) Opening to the outside world-strengthening import and export trade

Shanghai is located on the coast and has many coastal ports. It is the gateway between China, Japan and South Korea. It is necessary to build an import and export logistics system, build a high-speed through train to the international market, and greatly improve the convenience of import and export trade; establish an incentive system for the joint inspection department at the port, simplify the processing trade business procedures, improve the enterprise classification management, greatly save time, cost, and improve the economic benefits of the region; in addition, carry out foreign trade related activities regularly to attract domestic and foreign investment and strengthen cooperation and exchange, so as to promote import and export trade and regional economic growth.

5) Stimulate the vitality of enterprises, especially private enterprises

Private enterprises have become the market subject of innovation and active economy, and most enterprises, as the market subject and commercial subject, 
have vitality only when they are full of vitality. Shenzhen has put forward the slogan of "industry first, enterprise as the big", and initiated four $90 \%$ systems, which are market-oriented, enterprise as the main body and industrialization as the purpose. At present, although there is a good growth trend in the number of new enterprises in Shanghai every year, there is still a big gap in the development of quality star. Strive to build Shanghai into an adventurer's paradise, support manufacturing enterprises to move towards "high-end, middle and high-end value chain and industrial chain to make enterprise ecosystem alive, and lay a good foundation for the transformation of new and old kinetic energy.

6) Build a group of talent gathering platform and create a strong entrepreneurial atmosphere

For a city, development is the goal, vitality is the source, and talent is the foundation. Seizing talents is seizing the future. At present, Shanghai should invest the goal of attracting talents to the top international talent gathering places such as Silicon Valley, New York Wall Street, Lunxiao financial city and so on. The treatment and platform provided for the introduction of talents are also of international standard. We should establish innovation and entrepreneurship base for overseas talents returning home, explore the introduction of high-level talents at home and abroad, especially top scientific research teams, explore the establishment of high-end talents green card system, and give citizens treatment to high-end talents who are inconvenient to settle down. Hold overseas talents exchange meeting every year to strengthen the innovation of talent system and mechanism, explore the whole chain service mechanism of high-end talents, stimulate the vitality of talent innovation and entrepreneurship, and Let them take root in Shanghai and let the flow of high-end talents live. We will introduce targeted policies to attract young talents and take the introduction of young talents as an important indicator of the construction of a vibrant city.

\section{Model Evaluation}

\subsection{Strengths and Weaknesses}

\subsubsection{Strengths}

- This paper skillfully uses the flow chart to show the modeling idea completely and clearly;

- This paper refers to a large number of materials and the research data of experts and scholars, selects and sorts out appropriate index data in all aspects and at multiple levels;

- With the help of SPSS software, through the factor analysis method, the data of many suitable indexes are simplified and dimensionality is reduced. On the basis of principal component analysis, many variables are integrated into a few comprehensive factors which can reflect most of the information of the original variables, and the correlation between the original variables and factors is reproduced;

- In order to make the conclusion more accurate, the lagging explanatory variables are introduced into the model, and the short-term and long-term ef- 
fects of economic policy transformation on economic vitality are analyzed;

- Use all kinds of software to learn from each other, improve the results, process the data and make all kinds of charts, which is simple and intuitive.

\subsubsection{Weaknesses}

- The selection of indicators of economic vitality measurement model is affected by subjective cognition;

- In order to make the index data in the model pass the kmo test and Bartlett spherical test, we can eliminate some indexes, which may reduce the effectiveness of the model in measuring regional economic vitality;

- In order to simplify the calculation and make the results more ideal, some secondary factors are ignored in the model, and some data are approximately processed.

\subsection{Error Analysis}

In task 1, we only select some main influencing factors in the evaluation index system of regional economic vitality. In fact, there are many more factors that affect the regional economic vitality, which may have some influence on the effectiveness of the results of the multiple regression model established below, and there are inevitable errors.

In the three studies of the short-term and long-term effects of economic policy transformation on regional economic vitality, we only consider the role of fiscal policy, but ignore the impact of monetary policy and other government regulation tools. In this paper, we will consider the impact of government monetary policy on regional economic vitality changes in the improvement of the 8 model, and improve the dynamic regression model of policy role.

\subsection{The Improvement of the Model [10]}

In task4, we set up a dynamic regression model to introduce the lagging value of fiscal expenditure, focusing on the short-term and long-term effects of the government's fiscal policy transformation on regional economic vitality. Below we give the most basic model formula used in task 3 :

$$
e c o=\alpha+\beta_{1} g d p+\beta_{2} r p+\beta_{3} e i r+\beta_{4} p r o+\beta_{5} b e+\beta_{6} b e(-1)+\varepsilon
$$

In practice, the Central Bank of a country often adjusts the economy through monetary policy tools, so we need to improve the model to reduce the error.

In the modern monetary system, the central bank usually issues money, and the commercial banks are responsible for taking deposits and making loans. After the commercial banks pay a certain reserve to the central bank, they can lend the remaining funds to the enterprises, so the reserve ratio has become one of the three magic weapons for the central bank to regulate the money supply of a country. It has the following relations:

$$
\begin{gathered}
m=B_{0} * k \\
k=\left(1+R_{c}\right) /\left(R_{d}+R_{e}+R_{c}\right)
\end{gathered}
$$


Among them, $m$ is the actual money supply, " $B_{0}$ " is the basic currency issued by the central bank, $k$ is the currency multiplier, " $R_{d}$ ", " $R_{e}$ ” and " $R_{c}$ ” are the statutory reserve ratio, the excess reserve ratio and the cash leakage ratio of commercial banks.

With the introduction of money supply as explanatory variable, the following impact model of economic policy transformation is finally constructed:

$$
e c o=\alpha+\beta_{1} g d p+\beta_{2} r p+\beta_{3} e i r+\beta_{4} p r o+\beta_{5} b e+\beta_{6} b e(-1)+\beta_{7} m+\beta_{8}(-1)+\varepsilon
$$

\subsection{Extension}

Factor analysis and multiple regression model are widely used in management decision-making of economy, science and technology, culture, military, environment and social development. It is often used to solve such problems as comprehensive evaluation, decision-making scheme selection, estimation and prediction, allocation of investment, etc., such as car washing mode, agricultural technology promotion and other real life problems.

\section{Conflicts of Interest}

The author declares no conflicts of interest regarding the publication of this paper.

\section{References}

[1] Jin, L. and Ran, H. (2016) Research on the Development Strategy of Rural Commercial Banks' Asset Management Business under the New Normal. Southwest Finance, No. 5, 3-8.

[2] He, R.Q. (2016) A Study on the Evaluation of Urban Economic Vitality in the Pearl River Xijiang Economic Belt. Thesis, Guangxi Normal University, Guilin.

[3] Kastner, S.L. (2012) Cross-Strait Tensions and Taiwan's Economic Vitality. In: Tsang, S., Ed., The Vitality of Taiwan, Palgrave Macmillan, London, 119-138. https://doi.org/10.1057/9781137009906_7

[4] Lu, X.L. and Guo, W.S. (2007) Comprehensive Evaluation Index System of Urban Economic Vitality. Statistics and Decision Making, No. 11, 77-78.

[5] Yin, H. (2018) Stimulating the Vitality of Creative Economy and Fostering New Urban Kinetic Energy. Pioneer, No. 3, 28-30.

[6] Li, C.J. (2018) Adhering to the Problem-Based Approach to Enhance Jilin's Economic Vitality. Jilin Party School Newspaper, 15 October 2018.

[7] Liu, X.B. (2017) The Most Dynamic City in the Future. China Economic Information, No. 17, 38-39.

[8] Jin, Y.J. (2007) Evaluation of Urban Economic Vitality in China. Geosciences, 27, 9-16.

[9] Li, P. and Yang, H.C. (2016) Study on the Spatial Distribution Pattern and Driving Force of New Urbanization in Pearl River Xijiang Economic Belt. Academic Forum, 39, 69-74.

[10] Gui, Y.Y. (2015) Mathematical Modeling. Shanghai University of Finance and Economics, Shanghai. 